\title{
Numerical Simulation and Assessment Research of Reinforced Concrete Slabs Damage under the Effect of Explosion Shock Wave
}

\author{
Changlin $\mathrm{HE}^{1,}$ a , Qigao $\mathrm{HU}^{2, \mathrm{~b}}$, Jinghan $\mathrm{LIU}^{3, \mathrm{c}}$ \\ 1, 2, 3, College of Basic Education, National University of Defense Technology, Changsha, Hunan \\ 410072, China \\ ahechangmeier@126.com, ${ }^{b} 13308492472 @ 189 . c n,{ }^{\circ} j i n g h a n 2919 @$ hotmail.com
}

\begin{abstract}
Keywords: explosion shock wave; reinforced concrete slab; numerical simulation; equivalent plastic strain; principal component analysis (PCA); damage assessment

Abstract. In order to assess the damage of reinforced concrete slabs under the effect of explosion shock wave, finite element models were built with LS-DYNA. Different models under four working conditions in TNT equivalence, reinforcement and slab thickness were considered. Equivalent plastic strain was brought up to indicate the damage of slabs and a damage assessment method was proposed based on principal component analysis (PCA) theory. The assessment result of the new method is consistent with that assessing according to the deflection in deformation direction, which illustrates that the multivariate statistical analysis method can be used to evaluate the damage of reinforced concrete slabs under the effect of explosion shock wave. The method is feasible and will be further applied to other damage assessment.
\end{abstract}

\section{Introduction}

Protective doors are key part of protective engineering, so damage assessment of them under the effect of blast load is significant. The damage data of different protective structures or components can usually be obtained through live-fire drills, field tests and other ways. However, these ways are sometimes difficult to achieve for some large structures or new, important equipment, considering the cost and uncontrollable experiment risks. Therefore using numerical simulation with aid of high performance computer to simulate and assess the damage of protective structures or components under the effect of explosion shock wave is of great significance. Nowadays, the development of numerical simulation is more and more mature, and simulation can be used to do further analysis and research on the same field tests. This paper proposed a new damage assessment method of reinforced concrete slabs under the blast load based on principal component analysis (PCA) theory, instead of using the deflection to indicate the plastic deformation of those slabs under the same circumstance in traditional way.

\section{Numerical Simulation in Comparison with Experiment Results}

\section{Introduction of the Experiment}

In the Ref.[1], field explosion tests on 12 reinforced concrete slabs were carried out in order to study the blast resistance of those slabs of different sizes as well as different reinforcements. The test setup is shown in Fig.1.

All of slabs are square and clamped-supported in one-way mode. The size of supporting direction expands with extra $50 \mathrm{~mm}$ for the convenience of supporting. The transverse and longitudinal reinforcements are both constructed using $6 \mathrm{~mm}$ diameter bar and the distance between each bar is 75 $\mathrm{mm}$. The reinforcement is HPB235, of which the yield strength is $395 \mathrm{MPa}$ and the ultimate strength is $501 \mathrm{MPa}$. The concrete has an average compressive strength of $40.45 \mathrm{MPa}$. With TNT charge in cake shape as the explosive, the displacement at the bottom of the middle position of the slab is measured by the steel needles in the fine sand. 


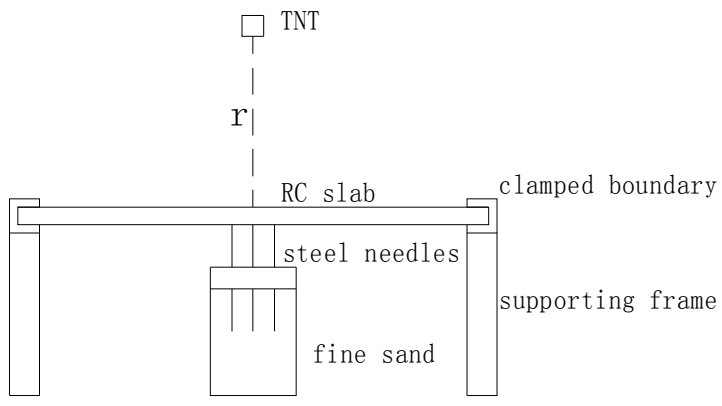

Fig.1 The diagram of test setup

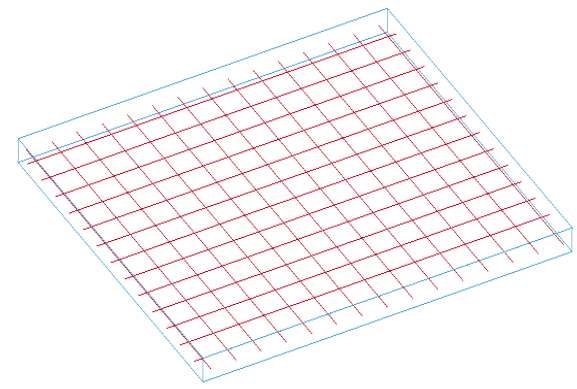

Fig.2 The model of the RC slab

\section{Finite Element Model}

\section{Geometric Model and Calculation Method}

According to the experiment, three dimensional dynamic software ANSYS is used to establish a geometric model. The slab size is $1100 \mathrm{~mm} \times 1000 \mathrm{~mm} \times 40 \mathrm{~mm}$, and the TNT charge is $310 \mathrm{~g}$ with detonation $40 \mathrm{~cm}$ to the surface of the slab. The unit system is $\mathrm{g}-\mathrm{cm}-\mu \mathrm{s}$. Because steel bars are wrapped in concrete, separate modeling method can be adopted since the slip between steel bars and concrete is ignored. Thus common node separate model of the reinforced concrete slab is built. Beam161 is chosen for rebars while Solid164 for concrete. The bars are built in the lower position of the middle in thickness direction. The element size of bars and concrete is $5 \mathrm{~mm}$ while the element size in thickness direction is $8 \mathrm{~mm}$. There are 225860 elements in total. In the two edges of the slab, all degrees of freedom of the nodes are constrained in order to simulate the clamped supporting boundary condition in the experiment. The geometric model is shown in Fig.2.

\section{Material Models and Strain Rate Effect}

For steel reinforcement, MAT_PLASTIC_KINEMATIC model with the option of including rate effects is used while MAT_CONCRETE_DAMAGE_REL3, whose major advantage is that it's based on a single user input parameter, the unconfined compressive strength for instance, and the remaining model parameters are automatically generated using a built-in algorithm and can also be modified by the user, is used for concrete. Dynamic Increase Factor(DIF) for steel is defiend by Cowper-Symonds model according to Ref.[2], that for the concrete compressive strength is defined according to CEB-FIP Model Code 1990[3], while that for the concrete tensile strength is defined according to Ref.[4].

For reinforcement strength:

$$
D I F=1+\left(\frac{\dot{\varepsilon}}{C}\right)^{1 / P},
$$

where ${ }^{\varepsilon}$ is the strain rate; $\mathrm{P}$ and $\mathrm{C}$ are strain rate parameters.

For concrete compressive strength:

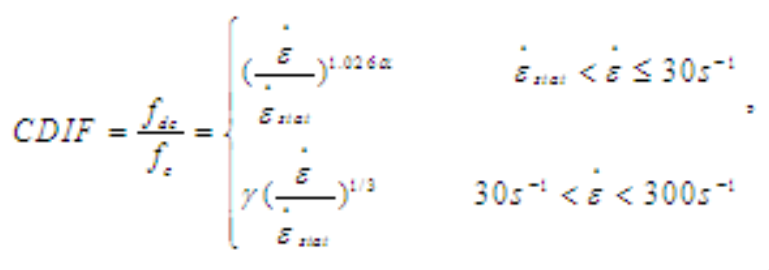

where $\mathrm{f}_{\mathrm{dc}}$ is the dynamic compressive strength at $\dot{\varepsilon} ; \mathrm{f}_{\mathrm{c}}$ is the static compressive strength at $\dot{\varepsilon}=\left(30 \times 10^{-6} \mathrm{~s}^{-1}\right) ; \alpha=1 /\left(5+0.9 \mathrm{f}_{\mathrm{c}}\right) ; \log \gamma=6.156 \alpha-2$. 
For concrete tensile strength:

$$
T D I F=\frac{f_{d t}}{f_{t}}=\left\{\begin{array}{lc}
\left(\frac{\dot{\varepsilon}}{\varepsilon_{s z}}\right)^{g} & \dot{\varepsilon}_{z s t}<\dot{\varepsilon} \leq 1 s^{-t} \\
\xi\left(\frac{\dot{\varepsilon}}{\varepsilon_{s z t}}\right)^{13} & 1 s^{-1}<\dot{\varepsilon}<160 s^{-1}
\end{array}\right.
$$

where $\mathrm{f}_{\mathrm{dt}}$ is the dynamic tensile strength at ${ }^{\dot{\varepsilon}} ; \mathrm{f}_{\mathrm{t}}$ is the static compressive strength at $\dot{\varepsilon}_{x=}\left(1 \times 10^{-6} \mathrm{~s}^{-1}\right)$; $\beta=1 /\left(10+0.8 \mathrm{f}_{\mathrm{c}}\right) ; \log \xi=6 \beta-2$.

The parameters of material models are shown in Table 1 and Table 2.

Table 1 Parameters for steel model

\begin{tabular}{|c|c|c|c|c|c|c|c|c|}
\hline $\begin{array}{c}\text { Mass } \\
\text { density } \\
{\left[\mathrm{kg} / \mathrm{m}^{3}\right]} \\
\end{array}$ & $\begin{array}{l}\text { Young's } \\
\text { modulus } \\
{[\mathrm{MPa}]}\end{array}$ & $\begin{array}{l}\text { Poisson's } \\
\text { ratio }\end{array}$ & $\begin{array}{c}\text { Yield } \\
\text { stress } \\
{[\mathrm{MPa}]} \\
\end{array}$ & $\begin{array}{c}\text { Tangent } \\
\text { modulus } \\
{[\mathrm{MPa}]}\end{array}$ & $\begin{array}{c}\text { Hardening } \\
\text { parameter } \\
\beta \\
\end{array}$ & $\begin{array}{c}\text { Strain rate } \\
\text { parameter } \\
\left.\mathrm{C}^{-1}\right]\end{array}$ & $\begin{array}{c}\text { Strain rate } \\
\text { parameter } \\
\mathrm{P} \\
\end{array}$ & Failure strain \\
\hline 7830 & 210000 & 0.28 & 395 & 5000 & 0 & 40 & 5 & 0.1 \\
\hline \multicolumn{9}{|c|}{ Table 2 Parameters for concrete model } \\
\hline \multicolumn{3}{|c|}{$\begin{array}{l}\text { Mass density } Y \\
{\left[\mathrm{~kg} / \mathrm{m}^{3}\right] \quad \text { modu }}\end{array}$} & $\begin{array}{l}\text { Poisson's } \\
\text { ratio }\end{array}$ & \multicolumn{2}{|c|}{$\begin{array}{c}\text { Compressive } \\
\text { strength } \\
{[\mathrm{MPa}]}\end{array}$} & $\begin{array}{l}\text { Unit conversi } \\
\text { actor for leng }\end{array}$ & \multicolumn{2}{|c|}{$\begin{array}{l}\text { Unit conversion } \\
\text { factor for stress }\end{array}$} \\
\hline \multicolumn{3}{|c|}{2550} & 0.2 & \multicolumn{2}{|c|}{40.45} & 0.3937 & \multicolumn{2}{|c|}{$1.45 \mathrm{E}+07$} \\
\hline
\end{tabular}

\section{Blast Load Model}

The blast load is simulated by CONWEP algorithm, which takes incident wave, reflected wave, and incident angel into consideration. The keyword *LOAD_BLAST is added into the keyword file. This method avoids the detailed modeling of the explosive charge and air, thus it can greatly reduce the element amount, resulting in saving the calculation cost.

\section{Results of Numerical Simulation}

The plastic deformation of reinforced concrete slabs under the effect of explosion shock wave can usually be indicated by the deflection in the deformation direction and the crevasse size of the lower surface of the slabs. Figure 3(a) shows the equivalent strain contours and figure 3(b) shows the damage of the experimental slab. The displacement time history curve of the node in the center of the lower surface of the slab is shown in Fig.4. While deflection and crevasse area radius in comparison with those in the experiment are shown in Table 3.

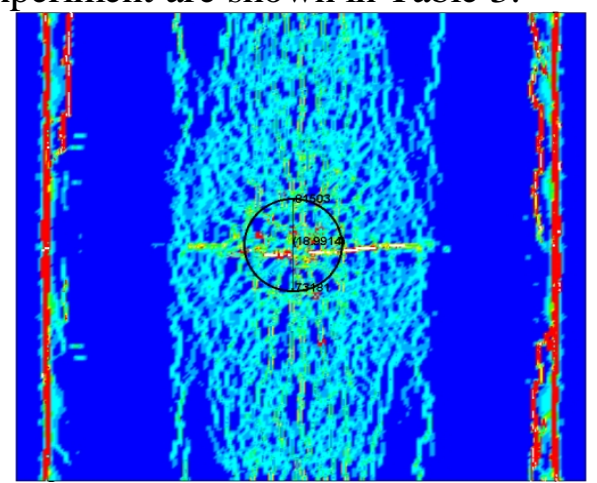

(a)

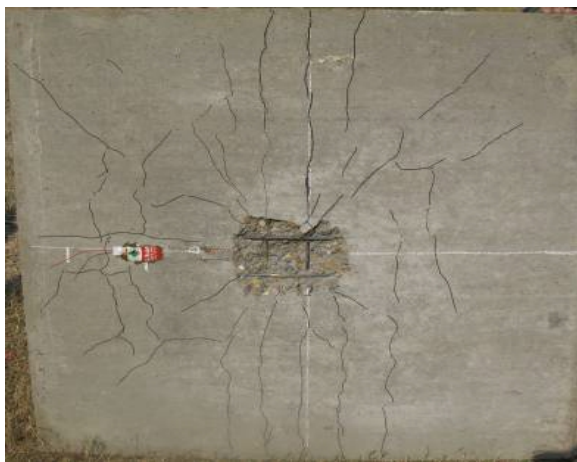

(b)

Fig.3 The equivalent strain contours and the damage of the experimental slab 


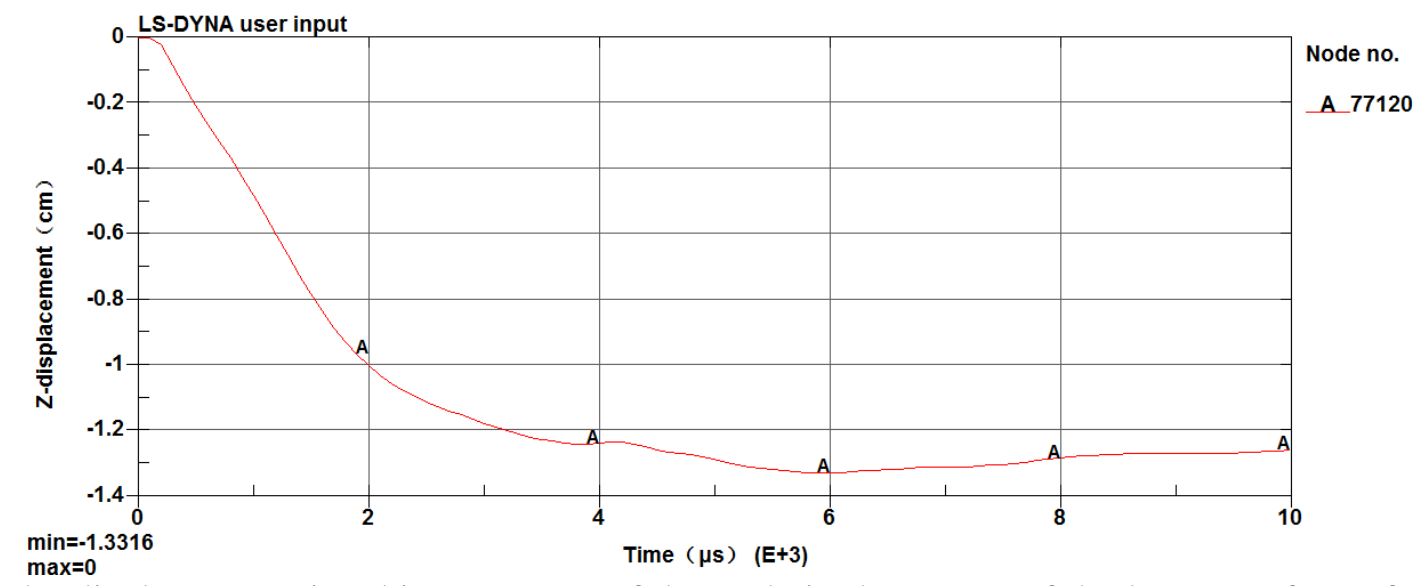

Fig.4 The displacement time history curve of the node in the center of the lower surface of the slab Table 3 Comparison of deflection and crevasse area radius of simulation and experiment

\begin{tabular}{ccc}
\hline & $\begin{array}{c}\text { Deflection of the node in the center } \\
\text { of the lower surface of the slab }[\mathrm{cm}]\end{array}$ & Crevasse area radius[cm] \\
\hline Experiment & 1.48 & 9.00 \\
Numerical simulation & 1.3316 & 9.4957 \\
Relative error & $-10.03 \%$ & $5.51 \%$ \\
\hline
\end{tabular}

As for the damage phenomenon of the slab, cracks and spallation are similar. It can be found out that the relative error of the deflection of the node in the center of the lower surface of the slab is $10.03 \%$, while that of crevasse area radius is $5.51 \%$. The results of numerical simulation and the experiment tend to be identical. The deflection of the node in the center of the lower surface of the slab in numerical simulation is less than that in the experiment, the reason might be that in numerical simulation, two edges of the slab are totally clamped while in the experiment, they are supported by steel frame, which is not absolutely clamped. Besides, parameters of materials in numerical simulation are not totally same as those in the experiment, thus leading to the difference in the results. However, as for simulation of explosion, relative errors can be accepted less than $20 \%$. So Table 3 shows that the calculation model is correct, and that parameters of materials and calculation method are reasonable, which can make the results reliable.

\section{Parameters Indicating the Damage of Reinforced Concrete Slabs}

There are many kinds of parameters used to indicate the damage of reinforced concrete slabs nowadays. For example, crater depth and diameter are often used to indicate the damage of target plate for penetration research; deflection in the deformation direction is usually used in explosion study.In Ref.[5],ductility ratio and bearing angel are used to assess the damage of reinforced concrete slabs under blast load; while in Ref.[6] residual bearing capacity and bearing capacity difference before and after explosion are proposed.

In damage mechanics, different damage variable is chosen for different damage mechanism. It can be a scalar, a first order vector, a second order tensor and even a four steps tensor[7]. But nearly all of damage variable is closely related to strain. Definitions of three damage variables are given in Ref.[8], and it is proven that they all change in power function with macro-strain. Ref.[9] also shows that damage variable increases in the process of plastic damage as strain increases through experiments.

A large number of damage data can be obtained using LS-PREPOST after simulating the damage model of the reinforced concrete slab under blast load. Equivalent plastic strain is a parameter which can simplify 6 strain components $\left(\varepsilon_{\mathrm{x}}, \varepsilon_{\mathrm{y}}, \varepsilon_{\mathrm{z}}, \varepsilon_{\mathrm{xy}}, \varepsilon_{\mathrm{yz}}, \varepsilon_{\mathrm{zx}}\right)$ in $3 \mathrm{D}$ coordinates as one dimensional description $\left(\varepsilon_{\mathrm{e}}\right)$. Therefore, equivalent plastic strain will be used in the following paper to indicate the damage of reinforced concrete slabs under the effect of explosion shock wave. 


\section{Damage Assessment of Reinforced Concrete Slabs under Different Circumstances}

\section{Damage data sampling}

Four circumstances are simulated using LS-DYNA. The slab in section $\mathbf{1 . 2}$ is the first circumstance. While TNT charge changes from $310 \mathrm{~g}$ to $200 \mathrm{~g}$, the second slab is built; distance between each bar changes from $75 \mathrm{~mm}$ to $100 \mathrm{~mm}$ and thickness changes from $40 \mathrm{~mm}$ to $64 \mathrm{~mm}$, the third and the fourth one are respectively built. The maximum displacement of the node in the center of the lower surface of the slab of each circumstance is $1.3316 \mathrm{~cm}, 0.8079 \mathrm{~cm}, 1.4806 \mathrm{~cm}$ and $0.3785 \mathrm{~cm}$.

Due to the explosive is vertically above the center of the slabs, and taking symmetry into consideration, 3 sampling elements are picked in the $X$ axis direction, with each element is $15 \mathrm{~cm}, 30$ $\mathrm{cm}$ and $45 \mathrm{~cm}$ away from the center, as well as those 3 sample elements in $45^{\circ}$ diverging from $\mathrm{X}$ axis direction and $\mathrm{Y}$ axis direction respectively. There are 9 sample elements(s1, s2.....s9) of each slab in total as shown in Fig.5. Equivalent plastic strain values of each sample element are shown in Table 4.

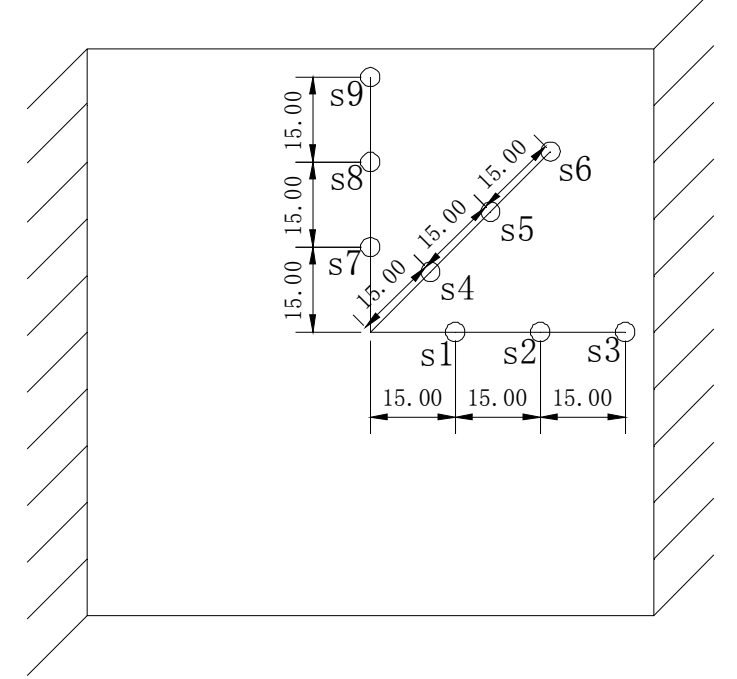

Fig.5 Sample element of the slab

Table 4 Equivalent plastic strain values of each sample element in 4 circumstances

\begin{tabular}{|c|c|c|c|c|c|c|c|c|c|}
\hline \multirow{2}{*}{ Circumstances } & \multicolumn{3}{|c|}{$\mathrm{X}$ axis direction } & \multicolumn{3}{|c|}{$\begin{array}{l}45^{\circ} \text { diverging from } \mathrm{X} \text { axis } \\
\text { direction }\end{array}$} & \multicolumn{3}{|c|}{$\mathrm{Y}$ axis direction } \\
\hline & 1 & 2 & 3 & 4 & 5 & 6 & 7 & 8 & 9 \\
\hline First slab & 1.9597 & 1.9251 & 1.6107 & 1.9852 & 1.9761 & 1.8390 & 1.6934 & 1.5204 & 1.9314 \\
\hline Second slab & 1.8112 & 1.6870 & 0.2169 & 1.9827 & 1.8692 & 1.7060 & 1.9890 & 1.9665 & 1.9791 \\
\hline Third slab & 1.9569 & 1.9196 & 0.2017 & 1.7211 & 1.8203 & 1.8758 & 1.9101 & 1.6617 & 1.7783 \\
\hline Fourth slab & 1.7285 & 1.7268 & 0.0686 & 1.9798 & 1.4856 & 1.4181 & 1.9037 & 1.7540 & 1.9674 \\
\hline
\end{tabular}

\section{Damage Assessment Process}

Principal component analysis method is introduced to assess the damage of reinforced concrete slabs under blast effect.

1) Write the evaluation matrix $X$, as shown in Eq. (4),

$$
X=\left(\begin{array}{lllllllll}
1.9597 & 1.9251 & 1.6107 & 1.9852 & 1.9761 & 1.8390 & 1.6934 & 1.5204 & 1.9314 \\
1.8112 & 1.6870 & 0.2169 & 1.9827 & 1.8692 & 1.7060 & 1.9890 & 1.9665 & 1.9791 \\
1.9569 & 1.9196 & 0.2017 & 1.7211 & 1.8203 & 1.8758 & 1.9101 & 1.6617 & 1.7783 \\
1.7285 & 1.7268 & 0.0686 & 1.9798 & 1.4856 & 1.4181 & 1.9037 & 1.7540 & 1.9674
\end{array}\right) .
$$

2) Process the matrix $X$ according to Z-Score method, referring to Eq. (5), and get non-dimensional matrix Y, as shown in Eq. (6), 


$$
y_{i j}=\frac{x_{i j}-\bar{x}_{j}}{s_{j}},
$$

where $x_{i j}$ is element of $\mathrm{X}$, while $\bar{x}_{j}$ and $s_{j}$ is mean value and variance of the column vector; $y_{i j}$ is element of Y,

$$
Y=\left(\begin{array}{ccccccccc}
0.8394 & 0.8805 & 1.4937 & 0.5201 & 0.8894 & 0.6226 & -1.4278 & -1.0970 & 0.1871 \\
-0.4640 & -1.0172 & -0.4230 & 0.5009 & 0.3845 & -0.0179 & 0.9085 & 1.2872 & 0.7014 \\
0.8148 & 0.8367 & -0.4439 & -1.4998 & 0.1535 & 0.7998 & 0.2849 & -0.3418 & -1.4636 \\
-1.1900 & -0.7000 & -0.6269 & 0.4788 & -1.4274 & -1.4044 & 0.2343 & 0.1515 & 0.5752
\end{array}\right) .
$$

3) Calculate the covariance matrix R of Y using MATLAB, and figure out eigenvalues $\lambda_{i}$ of R and eigenvectors for each eigenvalue. Then calculate the rate of contribution of each eigenvalue and accumulative contribution rate as shown in Table 5. (For $\lambda_{\mathrm{i}}=0$, it's not listed.)

Table 5 Eigenvalues and contribution rate of each eigenvalue

\begin{tabular}{cccc}
\hline Principal component & Eigenvalue & Contribution rate & Accumulative contribution rate \\
\hline F1 & 5.3978 & $59.98 \%$ & $59.98 \%$ \\
F2 & 2.3994 & $26.66 \%$ & $86.64 \%$ \\
F3 & 1.2028 & $13.36 \%$ & $100 \%$ \\
\hline
\end{tabular}

4)According to the principle of determining principal component shown in Eq. (7),

$$
\frac{\sum_{j=1}^{k} \lambda_{j}}{\sum_{j=1}^{n} \lambda_{j}} \geq 0.85
$$

two principal components, $\mathrm{F}_{1}$ and $\mathrm{F}_{2}$, are determined, and two corresponding eigenvectors are shown in Eq. (8) and Eq. (9),

$$
\begin{aligned}
& L_{1}=\left(\begin{array}{lllllllll}
-0.4206 & -0.4146 & -0.3040 & 0.1948 & -0.3095 & -0.3733 & 0.3034 & 0.3450 & 0.2734
\end{array}\right) \text {, } \\
& L_{2}=\left(\begin{array}{lllllllll}
-0.0820 & -0.0545 & 0.4552 & 0.5680 & 0.1035 & -0.1406 & -0.4138 & -0.1626 & 0.4820
\end{array}\right) \text {. }
\end{aligned}
$$

Two principal components can be established according to Eq. (10) and Eq. (11), and the result of damage assessment of reinforced concrete slabs under blast effect can be obtained combining with contribution rates of two principal components as shown in Eq. (12).

$$
\begin{aligned}
& F_{1}=Y\left(L_{1}\right)^{\prime}, \\
& F_{1}=Y\left(L_{1}\right)^{\prime}, \\
& F=0.5998 F_{1}+0.2666 F_{2}=\left(\begin{array}{c}
-0.9437 \\
0.9798 \\
-1.5157 \\
1.4796
\end{array}\right) .
\end{aligned}
$$

5)Rank the damage of four slabs according to the calculating results as shown in Table 6.And compare the ranking result with deflections of the node in the center of the lower surface of each slab.It can be found out that two ranking results are consistent. 
Table 6 Results of damage assessment of four slabs

\begin{tabular}{cccc}
\hline Circumstances & $\begin{array}{c}\text { Result of damage } \\
\text { assessment }\end{array}$ & $\begin{array}{c}\text { Ranking of damage } \\
\text { assessment }\end{array}$ & $\begin{array}{c}\text { Deflections of the node in the center of } \\
\text { the lower surface of each slab [cm] }\end{array}$ \\
\hline First slab & -0.9437 & 3 & 1.3316 \\
Second slab & 0.9798 & 2 & 0.8079 \\
Third slab & -1.5157 & 4 & 1.4806 \\
Fourth slab & 1.4796 & 1 & 0.3785 \\
\hline
\end{tabular}

\section{Conclusions}

Four reinforced concrete slabs under the effect of explosion shock wave were simulated using LS-DYNA. The fact that result of the first slab in numerical simulation corresponds to that of experiment proves that modeling method and parameters choosing is reasonable and correct. A new damage assessment method of reinforced concrete slabs under blast load was proposed based on principal component analysis (PCA ) theory. And the evaluation result was consistent with that according to the deflection of the node in the center of the lower surface of slabs, which indicates that the new assessing method can be used to evaluate the damage of reinforced concrete slabs under blast load. Equivalent plastic strain is brought up to indicate the damage, and this method can provide a reference for further research in damage assessment under much more complex circumstances.

\section{References}

[1] Wei WANG. Study on Damage Effects and Assessments Method of Reinforced Concrete Structural Members under Blast loading (In Chinese) [D]. Hunan: National University of Defense Technology, 2012.

[2] LS-DYNA KEYWORD USER'S MANUAL [M]. Livermore Software Technology Corporation, 2003.

[3] Du B.C.E.-I.CEB-FIP Model Code 1990[S].Redwood Books, Trowbridge, Wiltshire, UK, 1990.

[4] L. Javier Malvar, C. Allen Ross. Review of strain rate effects for concrete in tension[J].ACI Materials Journal, 1998, 95(6):735-739.

[5] Tianhua Li. Dynamic Response and Damage Assessment of reinforced Concrete Slabs Subjected to Blast Loading (In Chinese)[D].Shanxi: Chang'an University, 2012.

[6] Zhongxian LI, Yanchao SHI, Xiangsheng SHI. Damage analysis and assessment of RC slabs under blast load (In Chinese)[J].Journal of Building Structures, 2009, 30(6):60-65.

[7] Zhaoxia LI. Damage Mechanics and Its Application (In Chinese) [M].Beijing: Science Press, 2002.

[8] Yinyan Zhao, Li Zhou. Correlativity Analysis of Macro-And Meso-Damage Variables In The Tension of LY12CZ Board Specimen(In Chinese)[J].Acta Aeronautica et Astronautica Sinica, 1998, 19(1):95-97.

[9] Hongyao WU.Damage Mechanics(In Chinese) [M].Beijing: National Defend Industry Press, 1990:15-35.

[10] Yan CHEN, Zhen-sheng WANG, Shuang-shan MI. Simulation and Assessment of Target Plates Damage by Shock Wave of Certain Explosion(In Chinese) [J]. Journal of Ordnance Engineering College, 2009, 21(1):10-14. 